Original

\title{
Characterization of specimens obtained by different sampling methods for evaluation of periodontal bacteria
}

\author{
Ayako Okada, Kaoru Sogabe, Hiroaki Takeuchi, Masaaki Okamoto, \\ Yoshiaki Nomura, and Nobuhiro Hanada
}

\begin{abstract}
Department of Translational Research, School of Dental Medicine, Tsurumi University, Yokohama, Japan
\end{abstract}
(Received August 1, 2016; Accepted December 7, 2016)

\begin{abstract}
Quantitative analysis of periodontal bacteria is considered useful for clinical diagnosis, evaluation and assessment of the risk of periodontal disease. The purpose of this study was to compare the effectiveness of sampling of saliva, supragingival and subgingival plaque for evaluation of periodontal bacteria. From each of 12 subjects, i) subgingival plaque was collected from the deepest pocket using a sterile paper point, ii) stimulated whole saliva was collected after chewing gum, and iii) supragingival plaque was collected using a tooth brush. These samples were sent to the medical examination laboratory for quantitative analysis of the counts of three periodontal bacterial species: Porphyromonas gingivalis, Treponema denticola, and Tannerella forsythia. The proportions of these bacteria in subgingival plaque were higher than those in saliva or supragingival plaque, but lower in subgingival plaque than in saliva or supragingival plaque. In several cases, periodontal bacteria were below the levels of detection in subgingival plaque. We concluded that samples taken from subgingival plaque may be more useful for evaluating the proportion of periodontal bacteria in deep pockets than is the case for other samples. Therefore, for evaluation of periodontal bacteria, clinicians should consider the characteristics of the specimens
\end{abstract}

Correspondence to Dr. Yoshiaki Nomura, Department of Translational Research, School of Dental Medicine, Tsurumi University, 2-1-3 Tsurumi, Tsurumi-ku, Yokohama, Kanagawa 230-8501, Japan

Fax: +81-45-573-2473 E-mail: nomura-y@tsurumi-u.ac.jp

J-STAGE Advance Publication: November 17, 2017

doi.org/10.2334/josnusd.16-0573

DN/JST.JSTAGE/josnusd/16-0573 obtained using different sampling methods.

Keywords: sampling; periodontal bacteria; periodontal disease.

\section{Introduction}

Periodontitis is a common chronic oral disease in which oral bacteria play an important role in initiation, progression and recidivation. Although the oral cavity provides an environment for approximately 700 bacterial species, only a small proportion, known as periodontal bacteria, cause inflammation of periodontal tissue and subsequent bone and periodontal tissue destruction (1). Among the periodontal bacteria, three species-Porphyromonas gingivalis ( $P$. gingivalis), Tannerella forsythia ( $T$. forsythia), and Treponema denticola (T. denticola) - are categorized together based on their association with severe forms of periodontal disease (2). Intensive in vitro studies of these periodontal bacteria have been conducted with regard to their pathogenicity and virulence $(3,4)$.

There has been considerable research interest in the location, prevalence, and quantity of periodontal bacteria in the field of health and periodontal disease. Quantitative analysis of periodontal bacteria in clinical specimens, such as saliva, supragingival plaque and subgingival plaque, is important for diagnosis, evaluation, and risk assessment of patients with periodontal disease or who are prone to it. Using real-time PCR methods (5-7), clinicians can easily evaluate these periodontal bacteria and their association with clinical symptoms (8-12).

For microbiological diagnosis of periodontal diseases, subgingival plaque is commonly used for detection and quantitation of bacterial species (13-20). Using even tiny samples, PCR has proven to be a valuable method for 
detection of periodontal bacteria in periodontal pockets (21-26). The reproducibility of this approach is high, and the accuracy of testing is reportedly sufficient $(18,27-29)$. However, a larger number of sampling sites may create difficulties in a clinical or epidemiological context, and therefore selection of appropriate subgingival sampling sites becomes a critical consideration.

Periodontal bacteria in subgingival plaque are continuously washed into saliva from the gingival crevicular fluid (30). Therefore, it seems reasonable to employ PCR detection methods for samples of whole saliva in order to screen for the presence of periodontal pathogens in the human oral cavity. P. gingivalis and T. denticola have been detected more frequently in whole saliva in comparison to pooled periodontal pocket samples (30). Whole saliva may therefore be a convenient alternative to sampling of individual gingival pockets for determination of subgingival bacterial species (30-34).

Recently, advances in pyrosequencing have made it possible to investigate the oral microbiome, which is closely associated with many diseases, and also resident pathogenic oral bacteria. For such pyrosequencing, large samples are necessary.

As described above, there are conflicting opinions about the advantages and disadvantages of various sample sources for analysis of gingival bacteria. The aim of the present study was to compare the characteristics and effectiveness of saliva, subgingival plaque and supragingival plaque as samples for evaluation of periodontal bacteria.

\section{Materials and Methods}

\section{Subjects and clinical assessment}

Twelve subjects ( 6 men and 6 women, mean age $44.5 \pm$ 18.1 years) participated in this study. All were systemically healthy, possessed at least 20 teeth, and had not taken systemic antibiotics, anti-inflammatory drugs, or immunosuppressive drugs within 3 months prior to the investigation. Bleeding on probing (BOP) and probing pocket depth (PPD) were recorded at 6 sites per tooth (mesiobuccal, buccal, distobuccal, mesiolingual, lingual, and distolingual). Informed consent was obtained from each subject before the clinical examinations, and the protocol was approved by the institutional review board of Tsurumi University (\#1229).

\section{Sample collection}

For collection of subgingival plaque, the deepest pocket was selected $(5.58 \pm 2.57 \mathrm{~mm})$. After removal of the plaque from the selected site, a sample was taken by inserting two sterile \#40 paper points (Zipperer Absorbent Paper
Points, VDW GmbH, Munich, Germany) consecutively into the periodontal pocket for $10 \mathrm{~s}$. Whole saliva was collected after each subject had chewed on a gum base containing neither fragrance nor flavored ingredients for $5 \mathrm{~min}$. Supragingival plaque samples were collected by total tooth-brushing for $2 \mathrm{~min}$, followed by immersion of the toothbrush with the attached plaque in sterilized phosphate-buffered saline. Each sample thus collected was centrifuged at $3,000 \mathrm{rpm}$ for $5 \mathrm{~min}$ at $4^{\circ} \mathrm{C}$. All the samples were collected in the order described above and then immediately sent to a medical examination laboratory (BML Corporation, Tokyo, Japan) for bacterial analysis $(7-9,12)$.

\section{Quantification of periodontal bacteria from saliva, supragingival plaque and subgingival plaque}

Quantitative analysis of $P$. gingivalis, T. denticola, T. forsythia and total bacteria was performed using a modification of the Invader PLUS assay $(5,6)$. Briefly, bacterial DNA was extracted using a commercial kit (MagNA Pure LC Total Nucleic Acid Isolation Kit, Roche, Basel, Switzerland). Primary probes and Invader oligos were used as described previously $(7,12)$. Each tube contained $15 \mu \mathrm{L}$ of reaction mixture containing $50 \mu \mathrm{M}$ dNTP, $700 \mathrm{nM}$ primary probe, $70 \mathrm{nM}$ Invader oligo, $2.5 \mathrm{U}$ polymerase chain reaction (PCR) enzyme (EagleTaq DNA polymerase, Roche), and the Invader core reagent kit (Cleavase XI Invader core reagent kit, HOLOGIC, Marlborough, MA, USA) containing a fluorescence resonance energy transfer (FRET) mix, an enzyme $/ \mathrm{MgCl}_{2}$ solution and template DNA. The reaction mixtures were preheated at $95^{\circ} \mathrm{C}$ for $20 \mathrm{~min}$, followed by 35 cycles of $95^{\circ} \mathrm{C}$ for $1 \mathrm{~s}$ and $63^{\circ} \mathrm{C}$ for $1 \mathrm{~min}$, using an ABI PRISM 7900 (Applied Biosystems, Foster City, CA, USA). The fluorescence of carboxyfluorescein (FAM) excitation at $485 \mathrm{~nm}$ and emission at $530 \mathrm{~nm}$ was measured at the end of the thermal cycles. Standard curves were then constructed based on a crossing point determined by the fit point method. The proportions of the three pathogens within the total bacterial count were estimated as described previously $(10,35)$.

\section{Statistical analysis}

Descriptive analysis of the collected data was performed, and the results are presented as means \pm SD. One-way analysis of variance was used to compare bacterial counts and the proportion of each bacterial species among total bacteria. For between-group analyses, Bonferroni correction for multiple tests was applied. Correlations between sampling materials were evaluated in terms of the $\mathrm{R}^{2}$ and $P$ values. The regression formula was constructed based 

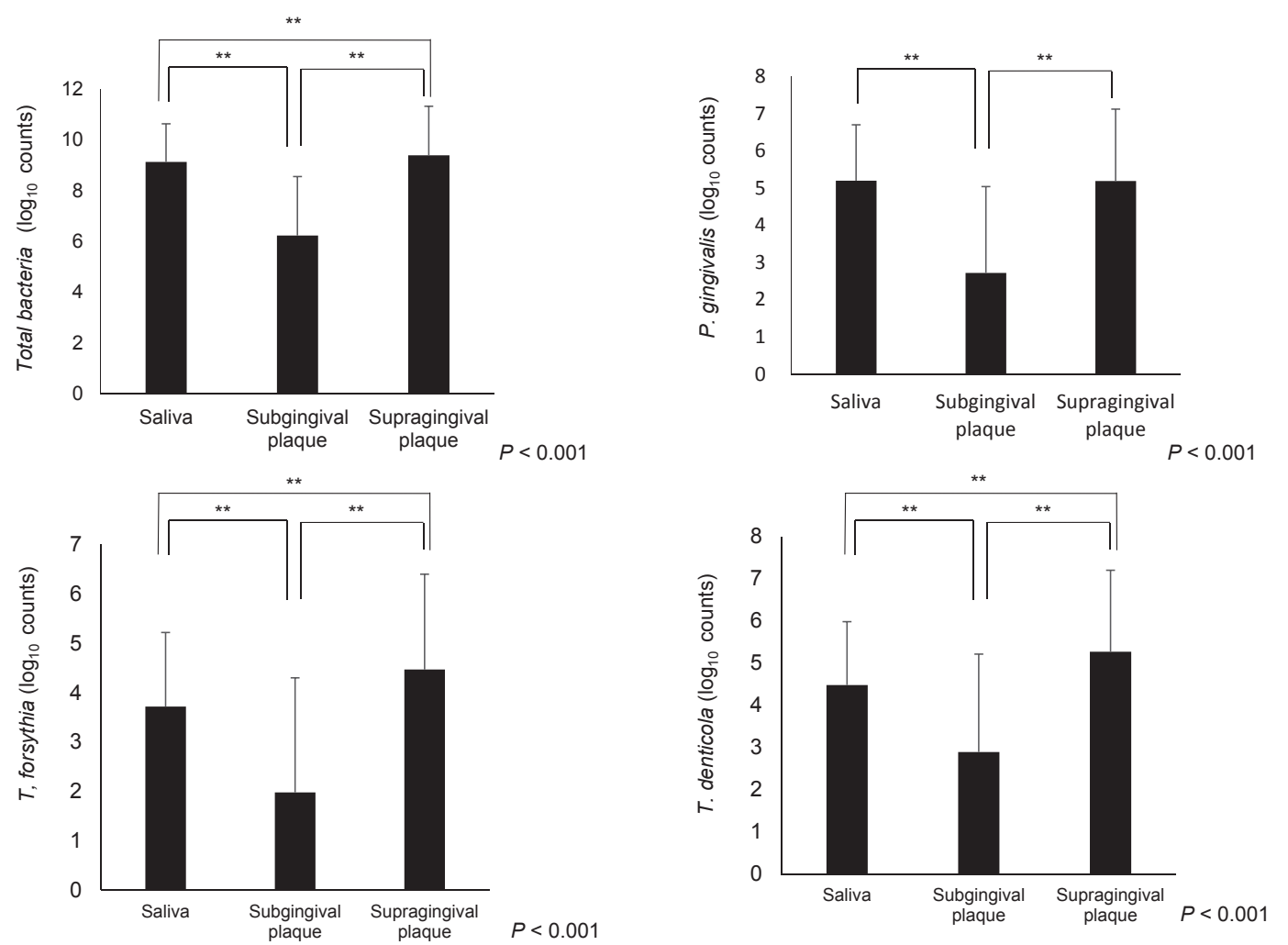

Fig. 1 Comparison of periodontal bacterial levels in saliva, subgingival plaque and supragingival plaque expressed as $\log _{10}$ counts. Bacterial levels in subgingival plaque were significantly lower than those in saliva and supragingival plaque.
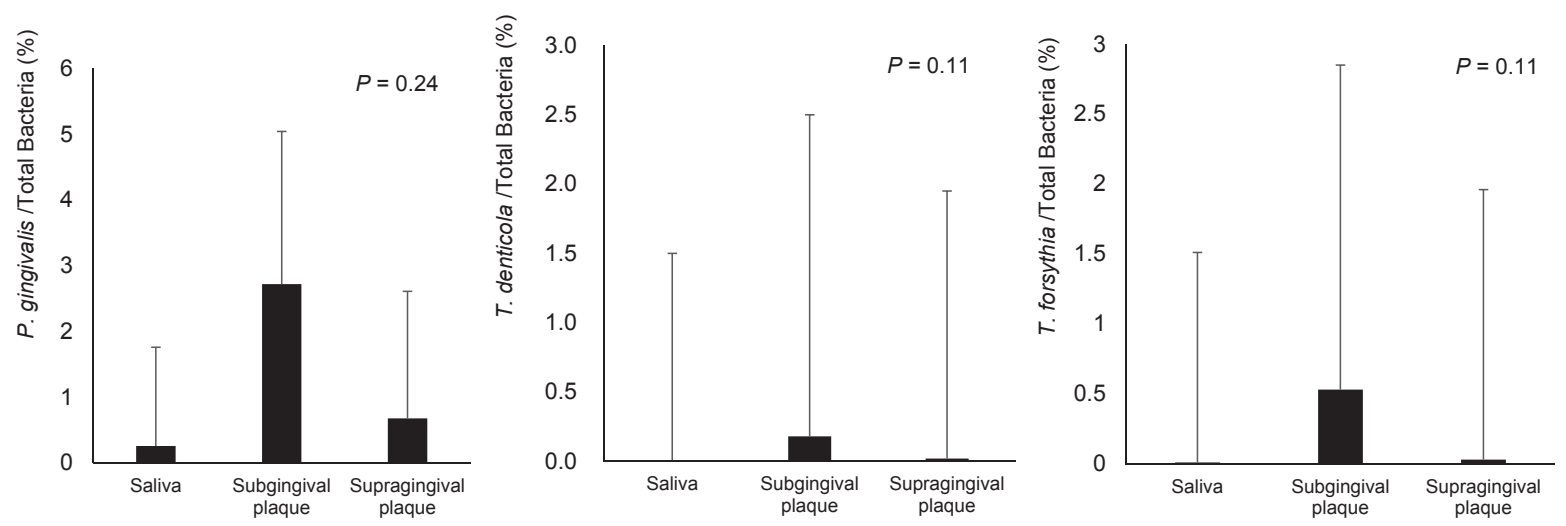

Fig. 2 Comparison of periodontal bacterial levels in saliva, subgingival plaque and supragingival plaque expressed as a percentage of total bacteria. Higher values for the three periodontal bacteria were observed in subgingival plaque samples. No statistically significant differences were observed.

on the least-squares method. The kappa test was used as a chance-corrected measure of agreement between sampling specimens, and $P$ values were calculated by the McNemar test. These analyses were performed using IBM SPSS Statistics ver. 19.0 software (IBM Japan, Tokyo, Japan). For analysis of systemic errors, the BlandAltman method was employed (36-42). Differences between two values were evaluated in terms of means and the $95 \%$ confidence interval $(95 \% \mathrm{CI})$. Random errors were evaluated by the test of no correlation of the mean values against difference of the two values. This analysis was performed usinf S-Plus software Ver 6.0 (NTT DATA, Tokyo, Japan).

\section{Results}

The participating subjects had $27.25 \pm 1.49$ remaining teeth, an average pocket depth of $3.19 \pm 0.97 \mathrm{~mm}$, and a BOP of $51.17 \pm 24.04 \%$. The quantitative data for total bacteria and periodontal bacteria in each of the samples are shown in Fig. 1. Statistically significant differences were observed between saliva and supragingival plaque samples, except for $P$. gingivalis. The mean total bacteria 

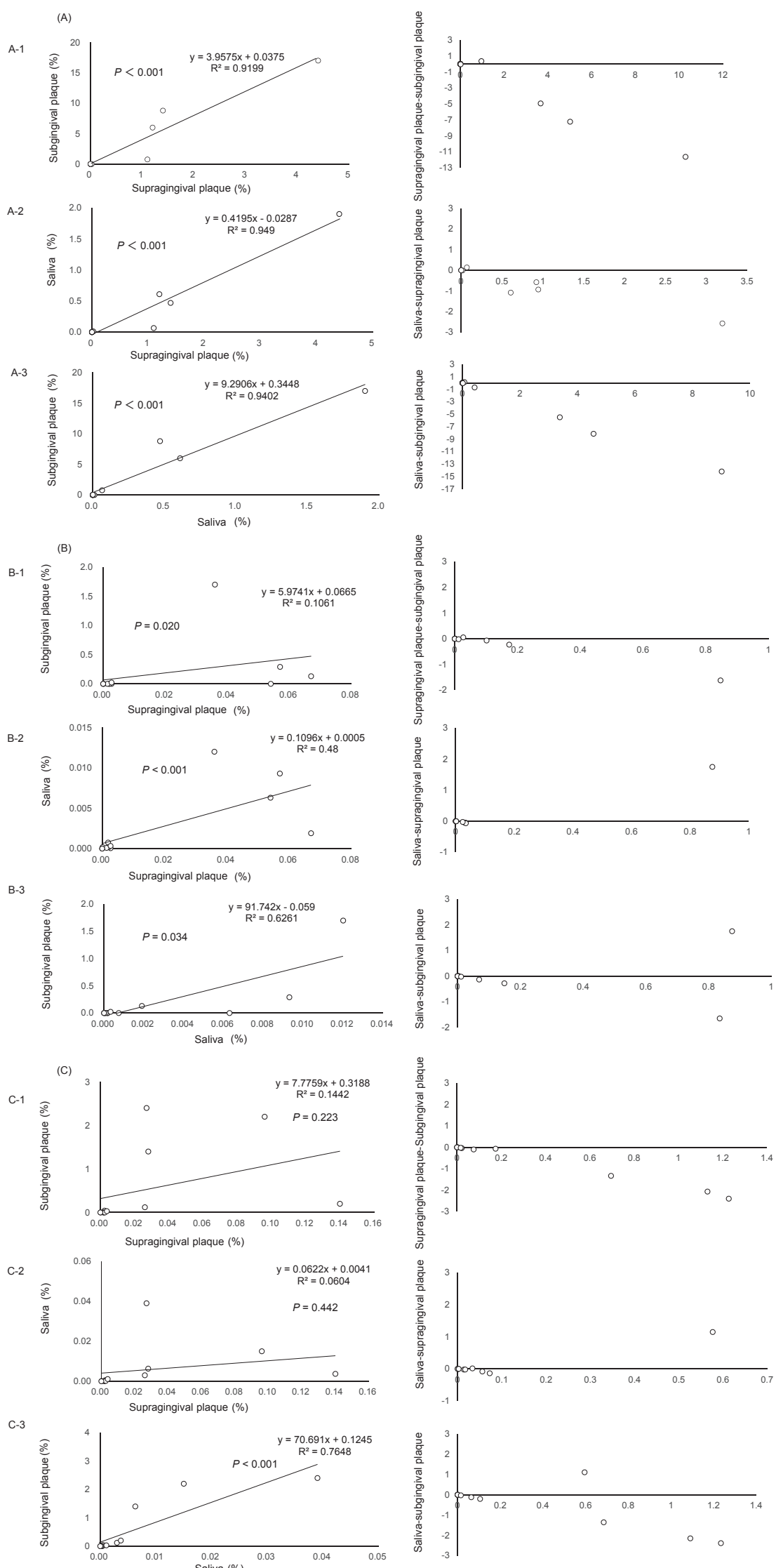

Fig. 3 Scatter plot of P. gingivalis (A), T. denticola (B), T. forsythia (C), and the corresponding Bland-Altman plot, which suggests extent of agreement by different measuring methods. 1, subgingival and supragingival plaque levels; 2 , saliva and supragingival plaque levels; 3 , subgingival plaque and sliva levels. 
Table 1 Results of Bland-Altman analysis for the various sample sources

\begin{tabular}{llccc}
\hline & & P. gingivalis & T. denticola & T. forsythia \\
\hline Saliva-supragingival plaque & Difference $(95 \% \mathrm{CI})$ & $-0.42(-0.98$ to 0.15$)$ & $0.13(-0.32$ to 0.58$)$ & $0.07(-0.30$ to 0.44$)$ \\
& Proportion of difference $(95 \% \mathrm{CI})$ & $0.22(-0.39$ to 0.82$)$ & $-0.88(-1.51$ to -0.26$)$ & $-0.86(-1.47$ to -0.25$)$ \\
& $P$ value & $<0.001$ & $<0.001$ & $<0.001$ \\
Saliva-subgingival plaque & Difference $(95 \% \mathrm{CI})$ & $-2.37(-3.73$ to -1.01$)$ & $-0.03(-0.57$ to 0.52$)$ & $-0.43(-1.07$ to 0.21$)$ \\
& Proportion of difference $(95 \% \mathrm{CI})$ & $0.39(-0.38$ to 1.16$)$ & $0.36(-0.41$ to 1.12$)$ & $-0.14(-0.93$ to 0.65$)$ \\
& $P$ value & $<0.001$ & $<0.001$ & $<0.001$ \\
Supragingival & Difference $(95 \% \mathrm{CI})$ & $-1.95(-3.21$ to -0.70$)$ & $-0.16(-0.59$ to 0.28$)$ & $-0.50(-1.10$ to 0.10$)$ \\
plaque-subgingival plaque & Proportion of difference $(95 \% \mathrm{CI})$ & $0.68(-0.05$ to 1.40$)$ & $0.55(-0.17$ to 1.26$)$ & $-0.23(-0.98$ to 0.52$)$ \\
& $P$ value & $<0.001$ & $<0.001$ & $<0.001$ \\
\hline
\end{tabular}

The table shows averages of the differences and proportions of differences, and their $95 \%$ confidence intervals (95\% CI). For the averages and differences in the proportions of periodontal bacteria among total bacteria between any two sample sources, statistically significant correlations were observed, suggesting random errors between the sampling methods.

Table 2 Comparison of bacterial detection frequencies from saliva, supragingival plaque and subgingival plaque samples

\begin{tabular}{|c|c|c|c|c|c|c|c|c|c|c|c|c|c|}
\hline & \multicolumn{13}{|c|}{ Saliva } \\
\hline & \multicolumn{5}{|c|}{ P. gingivalis } & \multicolumn{4}{|c|}{ T. denticola } & \multicolumn{4}{|c|}{ T. forsythia } \\
\hline & & - & + & kappa & $P$ value & - & + & kappa & $P$ value & - & + & kappa & $P$ value \\
\hline \multirow[t]{2}{*}{ Supragingival plaque } & - & 0 & 0 & - & - & 2 & 0 & 1.00 & 1.000 & 1 & 0 & 1.00 & 1.000 \\
\hline & + & 0 & 12 & & & 0 & 10 & & & 0 & 11 & & \\
\hline \multirow[t]{4}{*}{ Subgingival plaque } & - & 0 & 6 & - & - & 2 & 6 & 0.18 & 0.031 & 1 & 0 & 0.23 & 0.125 \\
\hline & + & 0 & 6 & & & 0 & 4 & & & 4 & 7 & & \\
\hline & \multicolumn{13}{|c|}{ Supragingival plaque } \\
\hline & & - & + & kappa & $P$ value & - & + & kappa & $P$ value & - & + & kappa & $P$ value \\
\hline \multirow[t]{2}{*}{ Subgingival plaque } & - & 0 & 6 & - & - & 2 & 6 & 0.18 & 0.031 & 1 & 4 & 0.23 & 0.125 \\
\hline & + & 0 & 6 & & & 0 & 4 & & & 0 & 7 & & \\
\hline
\end{tabular}

The kappa test was used to compare agreements between sampling sources. The McNemar test was used to calculate the $P$ values.

$\left(\log _{10}\right)$ count was 9.14 in saliva, 9.40 in supragingival plaque, and 6.24 in subgingival plaque, suggesting that the bacterial count detectable from subgingival plaque was less than that from saliva and supragingival plaque by more than a thousand fold. The mean count $\left(\log _{10}\right)$ of $P$. gingivalis was 5.20 in saliva, 5.19 in supragingival plaque, and 2.72 in subgingival plaque, the difference between subgingival plaque and other sources being more than one hundred-fold. Similar tendencies were also observed for T. denticola and T. forsythia.

When comparing bacterial levels between samples, percentages rather than absolute counts of targeted microorganisms should be used in order to adjust for variations in sampling. As shown in Fig. 2, when expressed as the proportion of periodontal bacteria among total bacteria, higher values were obtained from subgingival plaque samples for all three species of periodontal bacteria.

Figure 3 shows scatter plots of $P$. gingivalis (A), T. denticola (B), and T. forsythia (C) counts in saliva, subgingival plaque and subgingival plaque and the corresponding Bland-Altman plot. For $P$. gingivalis and T. denticola, significant linear correlations were observed between the sampling sources. The Bland-Altman plot demonstrated linear relationships between the sample sources (Table 1). With regard to the mean differences in the proportions of periodontal bacteria among total bacteria between the sampling sources and their 95\% confidence intervals $(95 \% \mathrm{CI})$, the lower limits of the 95\% CIs were all negative values and the upper limits were all positive. Therefore, no fixed errors were evident. However, the correlations between the means and the differences in the proportions of periodontal bacteria were all statistically significant. Random errors were observed between all of the sampling sources.

Cross-tabulation was performed to summarize the data for detection or non-detection of these periodontal bacterial species (Table 2). In several cases, periodontal bacteria were below the detection limit in subgingival plaque. Among 6 cases for $P$. gingivalis (50.0\%), 8 cases for $T$. denticola (66.7\%) and 5 cases for T. forsythia (41.7\%), T. denticola and T. forsythia were not detected among these pathogens in saliva and supragingival plaque samples in 2 cases and one case, respectively. 


\section{Discussion}

In this study, we compared the counts of periodontal bacteria and their proportions among total bacteria and examined the effectiveness of various sampling sources for their evaluation.

The periodontal bacteria investigated in this study are all obligate anaerobes. The proportions of these bacteria among total bacteria in subgingival plaque were higher than that in saliva or supragingival plaque. However, the counts of these bacteria in subgingival plaque were lower than those in saliva or supragingival plaque. For $P$. gingivalis and $T$. denticola, significant numerical correlations were found between sampling sources. However, in some cases, the plots were tightly packed around the origin, and in several cases periodontal pathogens were below the levels of detection in subgingival plaque. For these cases, the regression formula was not useful. Among the 12 cases, six (50\%) for P. gingivalis, eight (67\%) for T. forsythia and five (42\%) for $T$. denticola were below the levels of detection. Therefore, even if periodontal bacteria exist in the oral cavity, sampling of subgingival plaque from any individual periodontal pocket may yield a false negative result. This needs to be borne in mind in a clinical situation.

Even though significant differences were observed in bacterial counts obtained from saliva and supragingival plaque, no such differences were observed in the proportions of these bacteria. Also the coefficients of correlation for both the proportions and counts of bacteria between saliva samples and supragingival plaque were higher. This indicated that similar bacterial flora were present in both saliva and supragingival plaque, and that these bacterial flora differed from those in subgingival plaque.

In this study, $P$. gingivalis was detected in all samples of saliva and supagingival plaque, whereas it was detected in only $50 \%$ of subgingival plaque samples. In previous studies, the rates of detction of $P$. gingivlais in subgingival plaque samples were 56\% (43), 59\% (44), $88 \%$ (45), $76.4 \%$ (46), and $76 \%$ (47). In the present study, subgingival plaque samples were obtained from only one site. If pooled samples had been applied, the detection rate might have been higher.

The kappa values for detection of $T$. denticola and $T$. forthsia from saliva and supagingival plaque samples were 1.0, and that of detection from saliva and subgingival plaque was 0.18 , which indicated a very low match. A previous study yielded kappa values of 0.40 and 0.59 for detection of $T$. forthysia and $T$. denticola from saliva and subgingival plaque (48). This study also used pooled subgingival plaque samples from the deepest pocket in each quadrant.
There are conflicting opinions about the advantages and disadvantages of various sampling sources for evaluation of periodontal bacteria. For supragingival plaque, it is possible to collect dental plaque from all of the tooth surfaces, and simultaneous collection of supragingival plaque and a proportion of subgingival plaque is feasible. In addition, large samples can be obtained. Supragingival plaque is suitable for analyses requiring large samples, such as pyrosequencing for microbiome analysis. However, the bacterial count is dependent on the amount of sample collected. In a clinical situation, measuring the weight of dental plaque is almost impossible. Therefore, to evaluate or to compare the levels of bacteria, data expressed in terms of proportion may be more suitable than simple bacterial counts.

In contrast, saliva samples depend on salivary flow rate. Data expressed in terms of bacterial count and proportion may be useful for comparative purposes. In addition, collection of samples is simpler than for supragingival plaque. Therefore, saliva may be a more suitable sampling source for check-ups or mass screening.

Although subgingival plaque is useful for evaluation of bacteria in deep areas, the amounts of bacteria obtained are extremely small, possibly leading to false-negative results. In addition, samples collected from limited areas may not reflect the overall oral bacterial flora.

\section{Conflict of interest}

The authors have no conflict of interest to declare.

\section{References}

1. Paster BJ, Olsen I, Aas JA, Dewhirst FE (2006) The breadth of bacterial diversity in the human periodontal pocket and other oral sites. Periodontol 2000 42, 80-87.

2. Rôças IN, Siqueira JF Jr, Santos KR, Coelho AM (2001) "Red complex" (Bacteroides forsythus, Porphyromonas gingivalis, and Treponema denticola) in endodontic infections: a molecular approach. Oral Surg Oral Med Oral Pathol Oral Radiol Endod 91, 468-471.

3. Slots J, Ting M (1999) Actinobacillus actinomycetemcomitans and Porphyromonas gingivalis in human periodontal disease: occurrence and treatment. Periodontol 2000 20, 82-121.

4. Armitage GC (2010) Comparison of the microbiological features of chronic and aggressive periodontitis. Periodontol $200053,70-88$.

5. Sakamoto M, Takeuchi Y, Umeda M, Ishikawa I, Benno Y (2001) Rapid detection and quantification of five periodontopathic bacteria by real-time PCR. Microbiol Immunol 45, 39-44.

6. Tadokoro K, Yamaguchi T, Kawamura K, Shimizu H, Egashira T, Minabe M et al. (2010) Rapid quantification of 
periodontitis-related bacteria using a novel modification of Invader PLUS technologies. Microbiol Res 165, 43-49.

7. Tada A, Takeuchi H, Shimizu H, Tadokoro K, Tanaka K, Kawamura K et al. (2012) Quantification of periodontopathic bacteria in saliva using the invader assay. Jpn J Infect Dis 65, 415-423.

8. Yoshie H, Tai H, Kobayashi T, Oda-Gou E, Nomura Y, Numabe $Y$ et al. (2007) Salivary enzyme levels after scaling and interleukin-1 genotypes in Japanese patients with chronic periodontitis. J Periodontol 78, 498-503.

9. Jervøe-Storm PM, AlAhdab H, Semaan E, Fimmers R, Jepsen S (2007) Microbiological outcomes of quadrant versus fullmouth root planing as monitored by real-time PCR. J Clin Periodontol 34, 156-163.

10. Nomura Y, Shimada Y, Hanada N, Numabe Y, Kamoi K, Sato $\mathrm{T}$ et al. (2012) Salivary biomarkers for predicting the progression of chronic periodontitis. Arch Oral Biol 57, 413-420.

11. Preus HR, Gjermo P, Scheie AA, Baelum V (2015) The effect of metronidazole on the presence of $\mathrm{P}$. gingivalis and T. forsythia at 3 and 12 months after different periodontal treatment strategies evaluated in a randomized, clinical trial. Acta Odontol Scand 73, 258-266.

12. Morozumi T, Nakagawa T, Nomura Y, Sugaya T, Kawanami M, Suzuki F et al. (2016) Salivary pathogen and serum antibody to assess the progression of chronic periodontitis: a 24-mo prospective multicenter cohort study. J Periodontal Res 51, 768-778.

13. Asai Y, Jinno T, Igarashi H, Ohyama Y, Ogawa T (2002) Detection and quantification of oral treponemes in subgingival plaque by real-time PCR. J Clin Microbiol 40, 3334-3340.

14. Mager DL, Ximenez-Fyvie LA, Haffajee AD, Socransky SS (2003) Distribution of selected bacterial species on intraoral surfaces. J Clin Periodontol 30, 644-654.

15. Yoshida A, Suzuki N, Nakano Y, Oho T, Kawada M, Koga T (2003) Development of a 5'fluorogenic nuclease-based realtime PCR assay for quantitative detection of Actinobacillus actinomycetemcomitans and Porphyromonas gingivalis. J Clin Microbiol 41, 863-866.

16. Maeda H, Fujimoto C, Haruki Y, Maeda T, Kokeguchi S, Petelin M et al. (2003) Quantitative real-time PCR using TaqMan and SYBR Green for Actinobacillus actinomycetemcomitans, Porphyromonas gingivalis, Prevotella intermedia, tetQ gene and total bacteria. FEMS Immunol Med Microbiol 39, 81-86.

17. Gemmell E, Bird PS, Ford PJ, Ashman RB, Gosling P, Hu Y et al. (2004) Modulation of the antibody response by Porphyromonas gingivalis and Fusobacterium nucleatum in a mouse model. Oral Microbiol Immunol 19, 247-251.

18. Morillo JM, Lau L, Sanz M, Herrera D, Martín C, Silva A (2004) Quantitative real-time polymerase chain reaction based on single copy gene sequence for detection of periodontal pathogens. J Clin Periodontol 31, 1054-1060.

19. Suzuki N, Yoshida A, Nakano Y (2005) Quantitative analysis of multi-species oral biofilms by TaqMan real-time PCR. Clin Med Res 3, 176-185.
20. Hyvärinen K, Laitinen S, Paju S, Hakala A, Suominen-Taipale L, Skurnik M et al. (2009) Detection and quantification of five major periodontal pathogens by single copy genebased real-time PCR. Innate Immunol 15, 195-204.

21. Lin CY, Wong MY, Jeng JH, Chang WK, Kuo MY (1994) Rapid and specific detection of the leukotoxin sequences of Actinobacillus actinomycetemcomitans from periodontal pockets by the polymerase chain reaction. J Formos Med Assoc 93, 289-293.

22. Ashimoto A, Chen C, Bakker I, Slots J (1996) Polymerase chain reaction detection of 8 putative periodontal pathogens in subgingival plaque of gingivitis and advanced periodontitis lesions. Oral Microbiol Immunol 11, 266-273.

23. Riggio MP, MacFarlane TW, Mackenzie D, Lennon A, Smith AJ, Kinane D (1996) Comparison of polymerase chain reaction and culture methods for detection of Actinobacillus actinomycetemcomitans and Porphyromonas gingivalis in subgingival plaque samples. J Periodont Res 31, 496-501.

24. Watanabe K, Frommel TO (1996) Porphyromonas gingivalis, Actinobacillus actinomycetemcomitans and Treponema denticola detection in oral plaque samples using the polymerase chain reaction. J Clin Periodontol 23, 212-219.

25. Chen C, Ashimoto A, Sangsurasak S, Flynn MJ, Slots J (1997) Oral food consumption and subgingival microorganisms: subgingival microbiota of gastrostomy tube-fed children and healthy controls. J Periodontol 68, 1163-1168.

26. Jervøe-Storm PM, AlAhdab H, Koltzscher M, Fimmers R, Jepsen S (2010) Quantification of periodontal pathogens by paper point sampling from the coronal and apical aspect of periodontal lesions by real-time PCR. Clin Oral Investig 14, 533-541.

27. Lyons SR, Griffen AL, Leys EJ (2000) Quantitative real-time PCR for Porphyromonas gingivalis and total bacteria. J Clin Microbiol 38, 2362-2365.

28. Martin FE, Nadkarni MA, Jacques NA, Hunter N (2002) Quantitative microbiological study of human carious dentine by culture and real-time PCR: association of anaerobes with histopathological changes in chronic pulpitis. J Clin Microbiol 40, 1698-1704.

29. Boutaga K, van Winkelhoff AJ, Vandenbroucke-Grauls CM, Savelkoul PH (2005) Periodontal pathogens: a quantitative comparison of anaerobic culture and real-time PCR. FEMS Immunol Med Microbiol 45, 191-199.

30. Umeda M, Contreras A, Chen C, Bakker I, Slots J (1998) The utility of whole saliva to detect the oral presence of periodontopathic bacteria. J Periodontol 69, 828-833.

31. Rudney JD, Staikov RK (2002) Simultaneous measurement of the viability, aggregation, and live and dead adherence of Streptococcus crista, Streptococcus mutans and Actinobacillus actinomycetemcomitans in human saliva in relation to indices of caries, dental plaque and periodontal disease. Arch Oral Biol 47, 347-359.

32. Morillo JM, Lau L, Sanz M, Herrera D, Silva A (2003) Quantitative real-time PCR based on single copy gene sequence for detection of Actinobacillus actinomycetemcomitans and 
Porphyromonas gingivalis. J Periodontal Res 38, 518-524.

33. Mager DL, Haffajee AD, Socransky SS (2003) Effects of periodontitis and smoking on the microbiota of oral mucous membranes and saliva in systemically healthy subjects. J Clin Periodontol 30, 1031-1037.

34. Cortelli SC, Feres M, Rodrigues AA, Aquino DR, Shibli JA, Cortelli JR (2005) Detection of Actinobacillus actinomycetemcomitans in unstimulated saliva of patients with chronic periodontitis. J Periodontol 76, 204-209.

35. Tomita S, Komiya-Ito A, Imamura K, Kita D, Ota K, Takayama S et al. (2013) Prevalence of Aggregatibacter actinomycetemcomitans, Porphyromonas gingivalis and Tannerella forsythia in Japanese patients with generalized chronic and aggressive periodontitis. Microb Pathog 61-62, 11-15.

36. Bland JM, Altman DG (1986) Statistical methods for assessing agreement between two methods of clinical measurement. Lancet 1, 307-310.

37. Bland JM, Altman DG (1995) Comparing methods of measurement: why plotting difference against standard method is misleading. Lancet 346, 1085-1087.

38. Ludbrook J (2002) Statistical techniques for comparing measurers and methods of measurement: a critical review. Clin Exp Pharmacol Physiol 29, 527-536.

39. Shimada K, Kario K, Kushiro T, Teramukai S, Ishikawa Y, Kobayashi F et al. (2015) Differences between clinic blood pressure and morning home blood pressure, as shown by Bland-Altman plots, in a large observational study (HONEST study). Hypertens Res 38, 876-882.

40. Giavarina D (2015) Understanding Bland Altman analysis. Biochem Med (Zagreb) 25, 141-151.

41. Francq BG, Govaerts B (2016) How to regress and predict in a Bland-Altman plot? Review and contribution based on tolerance intervals and correlated-errors-in-variables models. Stat Med 35, 2328-2358.

42. Gómez-Polo C, Portillo Muñoz M, Lorenzo Luengo MC, Vicente P, Galindo P, Martín Casado AM (2016) Comparison of two color-difference formulas using the Bland-Altman approach based on natural tooth color space. J Prosthet Dent $115,482-488$.

43. Wahlfors J, Meurman JH, Väisänen P, Alakuijala P, Korhonen A, Torkko H et al. (1995) Simultaneous detection of Actinobacillus actinomycetemcomitans and Porphyromonas gingivalis by a rapid PCR method. J Dent Res 74, 1796-1801.

44. Mombelli A, Schmid B, Rutar A, Lang NP (2000) Persistence patterns of Porphyromonas gingivalis, Prevotella intermedia/ nigrescens, and Actinobacillus actinomyetemcomitans after mechanical therapy of periodontal disease. J Periodontol 71, 14-21.

45. Kumar PS, Griffen AL, Moeschberger ML, Leys EJ (2005) Identification of candidate periodontal pathogens and beneficial species by quantitative $16 \mathrm{~S}$ clonal analysis. J Clin Microbiol 43, 3944-3955.

46. Gajardo M, Silva N, Gómez L, León R, Parra B, Contreras A et al. (2005) Prevalence of periodontopathic bacteria in aggressive periodontitis patients in a Chilean population. $\mathrm{J}$ Periodontol 76, 289-294.

47. Cortelli JR, Cortelli SC, Jordan S, Haraszthy VI, Zambon JJ (2005) Prevalence of periodontal pathogens in Brazilians with aggressive or chronic periodontitis. J Clin Periodontol 32, 860-866.

48. Haririan H, Andrukhov O, Bertl K, Lettner S, Kierstein S, Moritz A, Rausch-Fan X (2014) Microbial analysis of subgingival plaque samples compared to that of whole saliva in patients with periodontitis. J Periodontol 85, 819-828. 